Revista Destaques Acadêmicos, Lajeado, v. 13, n. 1, 2021. ISSN 2176-3070

DOI: http://dx.doi.org/10.22410/issn.2176-3070.v13i1a2021.2670

http://www.univates.br/revistas

\title{
O COMPORTAMENTO DOS CLIENTES DE CLÍNICA DE ESTÉTICA: UMA ANÁLISE JUNTO AOS CONSUMIDORES DA CIDADE DE SANTA CRUZ DO SUL
}

\author{
Jônatas Vieira Santos Stacke ${ }^{1}$
}

\begin{abstract}
Resumo: Este artigo objetivou investigar o comportamento dos clientes de clínicas de estética de Santa Cruz do Sul. Trata-se de uma pesquisa aplicada, de caráter descritivo, com abordagem quantitativa, na qual utilizou-se um questionário online para coleta de dados. No total, 162 respostas foram analisadas, através de técnicas estatísticas. Os resultados obtidos apontam que o perfil é formado por mulheres relativamente jovens, com renda entre um a quatro salários mínimos. O procedimento mais buscado é o embelezamento, enquanto as principais queixas são gordura localizada, celulite e acne. Verificou-se ainda que a descoberta desses espaços ocorre via redes sociais ou boca a boca e que, a eficácia/resultado do procedimento, a limpeza/higiene e profissionais qualificados são os atributos mais valorizados na hora da escolha. Para os negócios locais, aumentar a frequência das visitas é o grande desafio, já que, mesmo julgando os gastos com serviços estéticos necessários, a maioria dos consumidores vai ao estabelecimento sem periodicidade definida.
\end{abstract}

Palavras-chave: Marketing, comportamento do consumidor, decisão de compra, clínica de estética.

\section{INTRODUÇÃO}

O mercado de estética possui diversas áreas de atuação e oferece inúmeras oportunidades aos empresários, que podem operar na indústria, no comércio ou na prestação de serviços. Ao mesmo tempo, por ser um setor promissor, é natural que apareçam novos investidores a todo instante, o que aumenta a concorrência. Nesse ambiente tão disputado e dinâmico, a administração de marketing torna-se um elemento essencial para o sucesso do negócio.

Seguindo as ideias de Kotler e Armstrong (2015) e Dias (2003), é por meio do marketing que a organização cria valor e constrói relacionamentos

1 Graduado em Comunicação Social - Hab. Publicidade e Propaganda pela Unisc e acadêmico do curso de MBA em Marketing da Univates. 
sólidos com seus clientes, bem como adquire um diferencial competitivo, destacando-se de seus concorrentes. Entretanto, para satisfazer às necessidades de um mercado da melhor maneira possível, as empresas precisam entender verdadeiramente "as pessoas ou as organizações que usarão os produtos e serviços que estão tentando vender" (SOLOMON, 2011, p. 8).

Nesse sentido, observar o comportamento dos clientes de clínicas de estética auxilia a compreender as suas peculiaridades e o que eles realmente esperam dos procedimentos, dos produtos e do atendimento oferecido, da mesma maneira que permite constatar as influências e motivações por trás da sua decisão de compra. Com essas informações em mãos, as empresas podem entregar um serviço que, de fato, irá atender as expectativas de seus consumidores.

Frente ao exposto, o presente estudo busca responder ao seguinte problema: quem são e como se comportam os clientes de clínicas de estética da cidade de Santa Cruz do Sul? Para isso, definiu-se como objetivo geral, investigar o comportamento dos clientes de clínicas de estética da cidade de Santa Cruz do Sul. E como objetivos específicos estabeleceu-se: traçar o perfil dos clientes de clínicas de estética no município em questão; conhecer os seus hábitos de consumo e estilo de vida; descobrir as suas preferências de comunicação; e verificar o que os levam a escolher uma clínica de estética em detrimento de outra.

A pesquisa justifica-se pelo seu valor para as empresas do ramo de serviços de estética, em especial aquelas que atuam em Santa Cruz do Sul e região, visto que os resultados encontrados podem auxiliar os gestores na tomada de decisão e na construção de estratégias de marketing mais embasadas e seguras, deixando de agir apenas na intuição.

\section{REFERENCIAL TEÓRICO}

\subsection{Marketing}

O marketing constitui um campo multidisciplinar e está em constante evolução. Em razão disso, existe uma vasta quantidade de conceitos para o termo na literatura, alguns mais complexos e outros bem específicos. $\mathrm{Na}$ definição mais recente da American Marketing Association, "marketing é a atividade, conjunto de instituições e processos para criar, comunicar, entregar e oferecer trocas com valor para os consumidores, clientes, parceiros e sociedade em geral" (AMA, 2017).

Kotler e Armstrong $(2015$, p. 3) acreditam que o marketing é responsável por construir fortes relacionamentos entre a empresa e seus clientes, com base na criação de valor, e complementam que seus dois objetivos centrais são: "atrair novos clientes, prometendo valor superior, e manter e cultivar os clientes atuais, entregando satisfação". Além de criar valor continuamente 
para o cliente, o marketing tem a função de gerar vantagens competitivas duradouras para organização (DIAS, 2003), através da gestão do mix de marketing, um "conjunto de ferramentas táticas de marketing - produto, preço, praça, promoção - que a empresa combina para gerar a resposta que deseja no mercado-alvo" (KOTLER; ARMSTRONG, 2015, p. 57).

Para Kotler e Keller (2012, p. 348), o produto não é apenas algo tangível, mas "tudo o que pode ser oferecido a um mercado para satisfazer uma necessidade ou um desejo, incluindo bens físicos, serviços, experiências, eventos, pessoas, lugares, propriedades, organizações, informações e ideias". Já o preço é a "soma de todos os valores dos quais os consumidores abrem mão para obter os benefícios de se ter ou utilizar um produto ou serviço" (KOTLER; ARMSTRONG, 2015, p. 318).

A praça, também denominada ponto de venda ou canal de distribuição, tem a finalidade de "tornar um produto ou serviço disponível para o consumo ou o uso de um consumidor ou usuário organizacional" (KOTLER; ARMOSTRONG, 2015, p. 375). Mais conhecida como comunicação, a promoção é o meio pelo qual a empresa busca informar, persuadir e lembrar os consumidores sobre os seus produtos ou serviços, bem como reforçar o seu posicionamento. Todavia, para oferecer uma mensagem com clareza, coerência e o máximo impacto, é preciso que todos os esforços de comunicação sejam planejados de modo integrado (KOTLER; KELLER, 2012).

Na visão de Futrell (2003), as empresas devem trabalhar cada uma dessas quatro variáveis estrategicamente, a fim de garantir que o produto certo esteja no local apropriado, a um preço atraente e com uma comunicação capaz de cativar os clientes. Campomar e Ikeda $(2006$, p. 11) acrescentam que a utilização de um mix de marketing adequado possibilita à organização "segmentar devidamente o mercado e posicionar corretamente seu bem (ou serviço), o que terá como consequência, muito provavelmente, a satisfação do cliente".

Nesse contexto, Ferrel e Hartline (2008, p. 113), ressaltam que "uma estratégia de marketing bem sucedida depende [...] de uma clara compreensão de quem são os consumidores, do que precisam, o que preferem e por que compram". Logo, o primeiro passo para criar valor para os consumidores é conhecer a fundo profundamente o seu comportamento.

\subsection{Comportamento do consumidor e os fatores que o influenciam}

No entendimento de Solomon (2011, p. 6), o comportamento do consumidor consiste no "estudo dos processos envolvidos quando indivíduos ou grupos selecionam, compram, usam ou descartam produtos, serviços, ideias ou experiências para satisfazerem necessidades e desejos". Para Blackwell, Miniard e Engel (2005), o comportamento do consumidor é uma ciência que reúne princípios da economia, psicologia, antropologia e outras disciplinas. Essas referências, segundo os mesmos autores, servem de suporte para o 
conhecimento da cultura, valores, crenças, desejos e tudo aquilo que interfere na formação da personalidade do indivíduo e que, consequentemente, influencia em seus processos de decisão de compra.

Destaca-se que existem quatro fatores que afetam fortemente o comportamento de compra das pessoas. São eles: culturais, sociais, pessoais e psicológicos. Os fatores culturais se subdividem em três elementos, queChurchill e Peter (2002) definem como: a) cultura: conjunto de valores e comportamentos aprendidos que são comumente usados na vida em sociedade para aumentar a sua probabilidade de sobrevivência; b) subcultura: grupos com valores e padrões de comportamentos diferentes da cultura geral, unidos a partir da nacionalidade, religião, raça, região geográfica, entre outras características; e c) classe social: hierarquia de status em que as pessoas são classificadas, em termos de valor e prestígio, com base em sua riqueza, habilidade e poder.

Já os fatores sociais, de acordo com Kotler e Keller (2012), abrangem: a) grupos de referência: grupos que exercem influência sobre o comportamento do indivíduo, tanto de forma direta, por meio de grupos de afinidade, que podem ser primários (família, amigos, vizinhos) ou secundários (grupos religiosos e profissionais), quanto de forma indireta, através de grupos de aspirações (o qual se espera pertencer) e grupos de dissociações (o qual os valores e comportamentos são rejeitados); b) família: grupo com maior influência, que se divide em família de orientação (pais e irmãos) e família de procriação (cônjuge e filhos); e c) papéis e status: as pessoas buscam escolher produtos e serviços condizentes com a posição que ocupam ou desejam ocupar na sociedade.

Os fatores pessoais, por sua vez, representam: a) idade e estágio no ciclo de vida: as necessidades das pessoas mudam conforme a idade ou momento de vida (casamento, nascimento de filhos); b) ocupação e circunstâncias econômicas: a profissão e a situação financeira do indivíduo (patrimônio, renda disponível) afetam seu padrão de consumo; c) personalidade e autoimagem: os consumidores escolhem produtos e serviços que combinam com a sua personalidade - um conjunto de traços psicológicos distintos - e que refletem a sua autoimagem; e d) estilo de vida: o padrão de vida de um indivíduo expresso em suas atividades, interesses e opiniões (KOTLER; KELLER, 2012).

Ainda, tem-se os fatores psicológicos, que Kotler e Armstrong (2015) dividem em quatro categorias: a) motivação: uma necessidade forte o suficiente para fazer com que a pessoa busque satisfazê-la; b) percepção: o processo pelo qual o indivíduo seleciona, organiza e interpreta as informações para dar significado ao mundo; c) aprendizagem: mudanças no comportamento de uma pessoa que ocorrem em virtude das suas experiências; e d) crenças e atitudes: a crença representa um pensamento descritivo que um indivíduo tem sobre alguma coisa, enquanto a atitude corresponde as suas avaliações, sentimentos e tendências, favoráveis ou não, a respeito de algo.

Percebe-se, então, que a "escolha do consumidor resulta de uma complexa inter-relação de fatores culturais, sociais, pessoais e psicológicos 
(KOTLER; ARMSTRONG, 2015, p. 162). E tão importante quanto avaliar todas essas forças que agem sobre o comportamento do consumidor, é verificar o modo como ele toma as suas decisões de compra.

\subsection{O processo de decisão de compra}

De acordo com Kotler e Armstrong (2015), ao efetuar a compra de um produto ou serviço, os consumidores passam por um processo de decisão que envolve cinco etapas: reconhecimento da necessidade, busca de informações, avaliação de alternativas, decisão de compra e comportamento pós-compra. Dessa forma, o processo de decisão do comprador inicia quando ele reconhece uma necessidade, ou seja, percebe uma diferença entre o seu estado atual e o estado ideal (BLACKWELL; MINIARD; ENGEL, 2005). E isso acontece tanto por estímulos internos (sede, fome) como por estímulos externos (anúncios, amigos) (KOTLER; ARMSTRONG, 2015).

Interessado em satisfazer a sua necessidade, o consumidor parte para a busca de informações, que segundo Blackwell, Miniard e Engel (2005), pode ser feita de forma passiva, na qual a pessoa fica mais receptiva às informações ao seu redor, ou ativa, quando ela decide procurar por mais informações nas mais variadas fontes. Kotler e Armstrong (2015) classificam essas fontes em: pessoais (família, amigos, vizinhos, conhecidos); comerciais (websites, propagandas, embalagens, vendedores, vitrines); públicas (mídia de massa, pesquisas de consumo, busca na internet); e experimentais (manuseio, exame, uso do produto/serviço).

Em seguida vem a avaliação das alternativas, momento em que o consumidor utiliza as informações encontradas para fazer sua escolha entre um conjunto final de marcas (KOTLER; ARMSTRONG, 2015). Nesse processo, os consumidores realizam um comparativo para "identificar a compra que lhes trará o maior valor" (CHURCHILL; PETER, 2000, p. 150), isto é, o melhor custo-benefício. Para isso, adotam como critérios de avaliação os atributos dos produtos ou serviços que julgam relevantes (segurança, preço, desempenho, etc.), dando um peso diferente para cada um deles, conforme o seu grau de importância (BLACKWELL; MINIARD; ENGEL, 2005; KOTLER, ARMSTRONG, 2015).

Após comparar as alternativas o consumidor finalmente forma uma intenção de compra. Em geral, a sua vontade é de adquirir a marca favorita, mas como ressaltam Kotler e Keller (2015), ainda existem dois fatores que podem interferir na sua decisão: a atitude dos outros (opinião de um amigo) e situações inesperadas (crise econômica). Portanto, uma intenção não significa, necessariamente, uma escolha de compra real.

Por último, temos a etapa do comportamento pós-compra, em que o consumidor toma atitudes após a aquisição, com base em sua satisfação ou insatisfação (KOTLER; ARMSTRONG, 2015). Para Blackwell, Miniard e Engel 
(2005), a satisfação é a avaliação pós-consumo de que a alternativa escolhida pelo menos atende ou excede as expectativas. Kotler e Keller (2012) alegam que um consumidor satisfeito provavelmente irá repetir a compra e recomendar o produto ou serviço para outras pessoas, enquanto um consumidor insatisfeito tende a não comprar mais, reclamar e falar mal da empresa. Assim, a "avaliação pós-compra é decisiva [...], pois, se um consumidor tem repetidamente experiências favoráveis com determinada marca, pode desenvolver lealdade a ela" (CHURCHILL; PETER, 2000, p. 151).

Como se pode notar, o processo de decisão do comprador começa bem antes da compra em si e se estende por muito tempo depois. E como lembram Kotler e Armstrong (2015), nem sempre todas as etapas são executadas pelos consumidores, sendo muitas vezes puladas ou até invertidas, assim como a transição entre uma e outra pode acontecer rapidamente ou lentamente. Para os mesmos autores, tudo depende da natureza do comprador, do produto ou serviço e da situação de compra.

Cabe ressaltar ainda que ao longo do processo de compra muitas outras marcas estão disputando a atenção do consumidor. Por essa razão, para se manterem competitivas, as empresas precisam acompanhar também as informações disponíveis sobre consumidores, concorrentes e evoluções do mercado.

\subsection{O mercado brasileiro de estética}

O mercado de estética, foco deste trabalho, possui uma ampla e complexa cadeia produtiva, que vai desde a indústria de cosméticos e equipamentos à negócios como salões de beleza, clínicas de estética e SPA's. Segundo estudo da Associação Brasileira da Indústria de Higiene Pessoal Perfumaria e Cosméticos (ABIHPEC), no período de 10 anos, compreendido entre 2009 e 2018, o PIB do Brasil cresceu apenas $0,7 \%$ e a indústria em geral recuou 1,5\%, enquanto a indústria de produtos de higiene pessoal, perfumaria e cosméticos (HPPC) evoluiu 4,1\% (ABIHPEC, 2019).

Para a mesma entidade, embora o desempenho de 2017 (4\%) e 2018 $(1,7 \%)$ tenham sido positivos, tal expansão não foi suficiente para neutralizar as perdas de $2015(-8,4 \%)$ e $2016(-5,1 \%)$, decorrentes das dificuldades econômicas do país. No entanto, ainda que os resultados estejam longe do que já foram um dia, percebe-se que o setor segue em crescimento, porém, numa velocidade mais lenta. Por outro lado, o estudo revela que em 2018 o Brasil continuou na quarta posição no ranking mundial de consumo de HPPC, movimentando US\$ 30 bilhões, e permaneceu líder absoluto na América Latina, com 48,6\% de participação nas vendas da região.

No que diz respeito às empresas que atuam no mercado de estética no Brasil, entre 2009 e 2016, o segmento de HPPC, que engloba corte e tratamento de cabelos, manicure, pedicure, atividades de estética e outros serviços de 
beleza, recebeu cerca de 645 mil novos MEI e mais 26 mil Microempresas (ME) e Empresas de Pequeno Porte (EPP) (ABIHPEC; SEBRAE, 2018). Em complemento a isso, a Associação Brasileira de Franchising (ABF) informa que o ramo de saúde, beleza e bem-estar manteve sua trajetória de recuperação gradual e alcançou $\mathrm{R} \$$ 31,9 bilhões de faturamento em 2018, o que representa um aumento de 6,3\% com relação ao ano anterior. Ainda, neste mesmo período, o ramo teve o maior número de redes com modelos de microfranquia no país (ABF, 2019).

Dentre os diversos fatores que contribuíram para o desenvolvimento do setor ao longo dos anos, destacam-se: o acesso das classes $\mathrm{D}$ e $\mathrm{E}$ aos produtos devido ao aumento da renda; os novos integrantes da classe $\mathrm{C}$ passaram a adquirir produtos de maior valor agregado; a crescente participação da mulher no mercado de trabalho; o uso de tecnologia de ponta e o aumento da produtividade, como redutor de preços; os lançamentos constantes de novos produtos, visando atender as necessidades do mercado, e o aumento da expectativa de vida (SEBRAE, 2017).

Em conformidade com uma pesquisa realizada pelo Serviço de Proteção ao Crédito (SPC Brasil) em parceria com a Confederação Nacional de Dirigentes Lojistas (CNDL), a preocupação com a própria imagem é uma marca do brasileiro. Os resultados do estudo revelam que seis em cada dez brasileiros consideram-se pessoas vaidosas e $65,7 \%$ concordam que cuidar da beleza não é um luxo, mas uma necessidade. Além disso, para quase a metade dos entrevistados $(49,4 \%)$, gastar dinheiro para melhorar a aparência física é um investimento que compensa, porque dá a sensação de felicidade e satisfação (SPC BRASIL; CNDL, 2016).

Diante dos dados apresentados, fica evidente que o mercado de estética se destaca na economia nacional e, por isto, merece, também, destaque nos estudos de marketing.

\section{PROCEDIMENTOS METODOLÓGICOS}

O estudo proposto consiste em uma pesquisa de natureza aplicada, uma vez que visa gerar conhecimento para resolver um problema concreto, ou seja, tem finalidade prática (VERGARA, 2016). Quanto à abordagem, trata-se de uma pesquisa quantitativa, que segundo Malhotra (2019), busca mensurar os dados e generalizar os resultados da amostra para a população alvo, por meio de análise estatística.

No que tange aos objetivos, a pesquisa é descritiva, pois se propõe a descrever as características de determinada população ou fenômeno e, também, estabelecer associações entre variáveis (GIL, 2018). Já com relação aos procedimentos técnicos, o estudo adotou o levantamento do tipo survey, no qual, conforme Gil (2018), realiza-se a interrogação direta de um grupo significativo de pessoas cujo comportamento se deseja conhecer, para em seguida extrair conclusões relativas aos dados coletados. 
Assim sendo, a população estudada envolveu clientes ativos de clínicas de estética da cidade de Santa Cruz do Sul. Conforme Malhotra (2019, p. 290), população alvo é a "coleção de elementos ou objetos que possuem as informações procuradas pelo pesquisador e sobre os quais devem ser feitas inferências". O tipo de amostragem foi não probabilística por conveniência, visto que a seleção das unidades amostrais ficou totalmente a cargo do entrevistador (MALHOTRA, 2019).

Como instrumento para coleta de dados, utilizou-se um questionário online criado no Google Forms, composto por 32 questões fechadas, organizadas em quatro blocos: perfil geral, hábitos de consumo e estilo de vida, preferências de comunicação e atributos para escolha de uma clínica de estética. A construção do último bloco, em especial, levou em consideração os atributos levantados nos trabalhos de Ribeiro, Thiesen e Tinoco (2013) e Meneguzzi (2016), além da opinião de dois especialistas da área de marketing e estética, que também auxiliaram na validação do questionário como um todo. Reforça-se ainda a presença de uma questão filtro no início do questionário, a fim verificar se o entrevistado costumava frequentar clínicas de estética em Santa Cruz do Sul. Se a resposta fosse negativa, o questionário era encerrado.

Antes da distribuição do questionário, buscou-se efetuar um pré-teste, com uma pequena amostra de respondentes, para averiguar se as perguntas estavam claras e objetivas. Como não houve nenhuma dificuldade nesta etapa, o link do questionário foi divulgado nas redes sociais e no WhatsApp, dando início a coleta de dados, que ocorreu entre os dias 26 de abril e 11 de maio de 2020.

Ao final do período determinado, as respostas foram validadas de acordo com a questão filtro. Obteve-se, então, um total de 162 respondentes que afirmaram frequentar clínicas de estética em Santa Cruz do Sul. Os resultados foram exportados, tabulados e processados no Microsoft Office Excel. Para analisar os dados, aplicaram-se técnicas estatísticas de distribuição de frequência, média e desvio padrão.

\section{ANÁLISE DOS RESULTADOS}

\subsection{Perfil geral}

Do total de respondentes da pesquisa, $93 \%$ se identificaram como mulheres e $7 \%$ como homens, o que mostra a predominância do gênero feminino entre os clientes de clínicas de estética em Santa Cruz do Sul. Já em relação a idade, mais da metade dos entrevistados (55\%) tem de 25 a 34 anos. $\mathrm{Na}$ sequência aparecem as faixas etárias de 18 a 24 anos (26\%), 35 a 44 anos $(10 \%), 45$ a 54 anos (7\%), 55 a 64 anos (2\%) e, por último, até 17 anos (1\%). Não houve participantes com mais de 65 anos. 
Portanto, trata-se de um público composto, essencialmente, por mulheres relativamente jovens. A partir dessa informação, já é possível imaginar alguns acontecimentos e transformações pertinentes ao seu estágio no ciclo da vida (KOTLER; KELLER, 2012), como o casamento, o nascimento dos filhos e o aparecimento dos primeiros sinais do envelhecimento.

Neste bloco de perguntas sobre o perfil observou-se ainda que a renda mensal dos respondentes ficou concentrada entre dois a quatro salários mínimos (31\%) e um a dois salários mínimos (28\%). Logo após, com 19\%, estão aqueles que recebem de quatro a dez salários mínimos. Salienta-se que $9 \%$ dos participantes não possuem renda e mesmo assim consomem serviços de estética, como aponta a tabela 1.

Tabela 1 - Distribuição dos entrevistados por renda mensal.

\begin{tabular}{l|c|c}
\hline Renda mensal & Número & Percentual \\
\hline Não possuo renda mensal & 15 & $9 \%$ \\
\hline Até R\$ 1.045 (1 salário mínimo) & 11 & $7 \%$ \\
\hline R\$ $1.045,01$ a R\$2.090 (1 a 2 salários mínimos) & 46 & $28 \%$ \\
\hline R\$ 2.090,01 a R\$ 4.180 (2 a 4 salários mínimos) & 50 & $31 \%$ \\
\hline R\$ 4.180,01 a R\$ 10.450 (4 a 10 salários mínimos) & 31 & $19 \%$ \\
\hline R\$ 10.450,01 a R\$ 20.900 (10 a 20 salários mínimos) & 5 & $3 \%$ \\
\hline Mais de R\$ 20.900 & 4 & $2 \%$ \\
\hline TOTAL & 162 & $100 \%$ \\
\hline
\end{tabular}

Fonte: Dados da pesquisa

Ao ter conhecimento da renda mensal dos entrevistados, não há como deixar de notar que apenas $5 \%$ deles ganham mais de dez salários mínimos. Isso só reforça que o aumento do poder de consumo das classes menos favorecidas é um dos grandes responsáveis pelo crescimento do mercado de estética nos últimos anos, como indica o Sebrae (2017).

Nesse contexto, vale lembrar que grandes marcas de cosméticos têm apostado neste nicho, com objetivo de conquistar também os consumidores com produtos mais acessíveis. Da mesma forma, as clínicas de estética que almejam expandir a sua participação no município precisam adaptar o seu mix de marketing para acompanhar as mudanças no comportamento dos consumidores das classes baixa e média.

\subsection{Hábitos de consumo e estilo de vida}

As visitas às clínicas de estética de Santa Cruz do Sul não costumam ser tão constantes entre os participantes da pesquisa, dado que quase metade dos entrevistados (48\%) alegam ir a este tipo de estabelecimento, mas sem uma 
frequência definida. Arrisca-se dizer que este seja, talvez, o maior desafio para os empresários da área. Oferecer serviços complementares aos principais e programas de fidelidade são possíveis caminhos para aumentar a recorrência dos clientes. Entre os consumidores assíduos, 31\% afirmam fazer uso dos serviços mensalmente, $10 \%$ semanalmente e $10 \%$ quinzenalmente.

Quando questionados sobre os procedimentos estéticos mais utilizados, grande parte dos entrevistados $(68 \%)$ apontam aqueles relacionados ao embelezamento, que envolvem serviços como design de sobrancelhas e extensão de cílios. Cerca de $74 \%$ das mulheres com idade entre 25 a 34 anos concordam com essa afirmação. Em seguida, praticamente empatados, estão os procedimentos de estética facial $(41 \%)$ e corporal (39\%). Manicure e depilação foram os serviços mais citados na alternativa "Outros" (5\%).

A diferença percentual dos procedimentos de embelezamento para os demais é bastante surpreendente. A alta demanda por este tipo de serviço, comumente encontrado em salões de beleza, revela uma oportunidade de negócio não somente para quem pretende empreender no segmento, mas, também, para as clínicas de estética que desejam diversificar seus serviços e gerar novas fontes de receita, destacando-se dos concorrentes.

Tendo em vista que as clínicas de estética atuam diretamente no tratamento de disfunções estéticas faciais e corporais, aproveitou-se para sondar as principais queixas dos entrevistados. Como expõe a tabela 2 , as três patologias que mais incomodam são: gordura localizada (55\%), celulite (44\%) e acne (40\%). Em "Outros" (2\%) foram mencionadas retenção de líquidos e pelos.

Tabela 2 - Principais queixas dos entrevistados (múltipla escolha).

\begin{tabular}{l|c|c}
\hline Principais queixas & Número & Percentual \\
\hline Gordura localizada & 89 & $55 \%$ \\
\hline Celulite & 72 & $44 \%$ \\
\hline Acne (cravos) & 65 & $40 \%$ \\
\hline Rugas (linhas de expressão) & 47 & $29 \%$ \\
\hline Olheiras & 43 & $27 \%$ \\
\hline Flacidez & 41 & $25 \%$ \\
\hline Manchas & 35 & $22 \%$ \\
\hline Estria & 30 & $19 \%$ \\
\hline Nenhuma & 5 & $3 \%$ \\
\hline Outros & 4 & $2 \%$ \\
\hline
\end{tabular}

Fonte: Dados da pesquisa

De certa forma, as informações apresentadas na tabela 2 ajudam a compreender parte das razões pelas quais os consumidores recorrem aos 
serviços de estética no município. Isso porque, ao manifestar suas insatisfações com a aparência, os respondentes reconhecem a existência de uma necessidade, ou seja, sentem que há uma diferença entre a situação atual e a desejada (BLACKWELL; MINIARD; ENGEL, 2005). Sabendo disso, as clínicas de estética locais podem explorar essas queixas comuns em sua comunicação, para despertar o interesse do consumidor e, consequentemente, dar início ao processo de decisão de compra, como ilustram Kotler e Armstrong (2015). Ou, ainda, ofertar novas possibilidades de tratamentos para essas disfunções, de modo a aprimorar o seu leque de serviços.

Com intuito de enriquecer a discussão, realizou-se o cruzamento dos dados das patologias e da faixa etária dos participantes do gênero feminino. Nisso, descobriu-se que a acne é considerada a principal queixa para maioria (56\%) das mulheres mais jovens (até 24 anos), seguida da gordura localizada $(52 \%)$ e da celulite $(48 \%)$. Para aquelas que têm entre 25 e 34 anos, a gordura localizada (58\%) e a celulite (51\%) continuam entre as primeiras queixas. O que muda é que as rugas assumem a terceira posição, com $37 \%$ dos votos.

A gordura localizada (67\%) e a celulite (47\%) também são as reclamações mais comuns das mulheres de 35 a 44 anos. Porém, as manchas surgem em terceiro lugar, sendo citadas por $40 \%$ delas. No ponto de vista das mulheres com idade acima de 45 anos, as patologias que mais incomodam são as rugas e a flacidez, ambas com $50 \%$ dos votos, e a gordura localizada, com $42 \%$.

Todas essas informações levantadas fortalecem a ideia de que as necessidades dos consumidores mudam conforme a idade e o estágio da vida, como sugerem Kotler e Keller (2012). Além disso, servem de subsídio para criar ações de marketing de forma mais segmentada, com base nos interesses do público.

Quanto aos gastos mensais com procedimentos estéticos, 33\% dos entrevistados declaram investir entre $R \$ 101$ e $R \$ 200$. Um ponto que chama atenção é que esse percentual sobe para $44 \%$ entre as mulheres que recebem de um a dois salários mínimos. Os demais gastam, por mês, entre R \$ 51 e 100 (24\%), até $\mathrm{R} \$ 50$ (16\%), entre R\$ 201 e R 300 (13\%), entre $\mathrm{R}$ \$ 301 e R \$ $400(6 \%)$, mais de $\mathrm{R} \$ 500$ (4\%) e entre R \$ 401 a R 500 (4\%).

Mais do que isso, buscou-se saber a opinião dos consumidores acerca dos gastos com beleza e estética (TABELA 3). Para atingir esse objetivo, os entrevistados deveriam indicar o seu grau de concordância com relação a duas afirmativas sobre o tema, sendo 1 para discordo totalmente e 5 para concordo totalmente. 
Tabela 3 - Opinião dos entrevistados sobre gastos com beleza e estética.

\begin{tabular}{l|c|c}
\hline Opinião sobre gastos com beleza e estética & Média & Desvio Padrão \\
\hline $\begin{array}{l}\text { Acredito que os gastos com procedimentos } \\
\text { estéticos são necessários }\end{array}$ & 4,10 & 0,97 \\
\hline $\begin{array}{l}\text { Acredito que os gastos com cosméticos são } \\
\text { necessários }\end{array}$ & 3,88 & 1,12 \\
\hline
\end{tabular}

Fonte: Dados da pesquisa

Ao analisar a tabela 3, nota-se que, no geral, os respondentes concordam parcialmente $(4,10)$ que os gastos com procedimentos estéticos são necessários. Já a média obtida na segunda afirmativa $(3,88)$ sugere que o gasto com cosméticos é algo conveniente para os entrevistados, mas não chega a ser essencial. Isso demostra que, segundo os conceitos sobre crenças e atitudes trazidos por Kotler e Armstrong (2015), os participantes pensam e agem de maneiras distintas com relação ao investimento em serviços e produtos de estética.

Para encerrar este bloco de perguntas sobre hábitos de consumo e estilo de vida, procurou-se aprender um pouco mais sobre as atividades e interesses dos consumidores (TABELA 4), na tentativa de verificar o quanto, de fato, eles estão engajados na busca de uma aparência melhor. Foi solicitado, então, aos participantes que indicassem a frequência com que realizam certas ações, sendo 1 para nunca e 5 para muito frequentemente.

Tabela 4 - Atividades e interesses dos entrevistados.

\begin{tabular}{l|c|c}
\hline Atividades e interesses & Média & Desvio Padrão \\
\hline Pratico exercícios físicos & 3,72 & 0,98 \\
\hline Me alimento de forma saudável & 3,54 & 0,81 \\
\hline $\begin{array}{l}\text { Utilizo produtos para complementar o trata- } \\
\text { mento feito na Clínica (home care) }\end{array}$ & 3,41 & 1,12 \\
\hline $\begin{array}{l}\text { Acompanho novidades relacionadas à beleza e } \\
\text { estética }\end{array}$ & 3,66 & 1,07 \\
\hline
\end{tabular}

Fonte: Dados da pesquisa

A partir das médias expostas na tabela 4, é possível observar que praticar exercícios físicos $(3,72)$, manter uma alimentação saudável $(3,54)$ e utilizar produtos para complementar o tratamento estético $(3,41)$ não são atividades tão presentes no dia a dia dos entrevistados. O curioso é que manter hábitos saudáveis é fundamental para potencializar, por exemplo, a redução da gordura localizada e melhorar o aspecto da celulite, principais queixas apontadas pelos participantes da pesquisa (TABELA 2). É aquela velha questão de que muitas pessoas ainda parecem acreditar na existência de uma "fórmula mágica", 
quando, na verdade, é a combinação desses cuidados com os procedimentos estéticos que proporciona o resultado esperado pelo paciente.

Embora a busca por informações relacionadas à beleza e estética também não seja muito frequente, a média 3,66 aponta que os respondentes têm interesse em saber mais sobre o assunto. Diante disso, a primeira coisa que as empresas do ramo devem fazer é entender em profundidade quais são os melhores canais para divulgar as suas novidades, a fim de desenvolver estratégias de comunicação mais eficazes.

\subsection{Preferências de comunicação}

Para a maioria dos clientes de clínicas de estética de Santa Cruz do Sul que responderam à pesquisa $(99 \%)$, a Internet é o meio de comunicação mais consumido. Em segundo lugar aparece a televisão (30\%), seguida do rádio $(12 \%)$ e dos jornais $(7 \%)$. A última opção foram as revistas, indicadas por apenas $1 \%$ dos entrevistados.

Frente a isso, não há dúvidas de que a Internet é uma ótima escolha para divulgação de serviços de estética, não só pela sua força, mas também pelos baixos custos de investimento se comparado as demais mídias. Por outro lado, as mídias tradicionais ainda têm sua relevância, visto que, quando somadas, a televisão, o rádio, os jornais e as revistas são consumidas por mais da metade (51\%) dos respondentes.

Para conhecer mais sobre o comportamento online dos entrevistados, questionou-se quais as mídias sociais que eles costumam acessar com mais frequência. Como mostra a tabela 5, o Instagram (94\%) e o WhatsApp (80\%) são as mídias sociais preferidas dos participantes. Posteriormente vem o Facebook (38\%) e o YouTube (24\%). Em “Outros" (4\%) foram citados o Twitter, o Telegram e o LinkedIn.

Tabela 5 - Mídias sociais mais acessadas pelos entrevistados (múltipla escolha).

\begin{tabular}{l|c|c}
\hline Mídias sociais mais acessadas & Número & Percentual \\
\hline Instagram & 153 & $94 \%$ \\
\hline WhatsApp & 130 & $80 \%$ \\
\hline Facebook & 62 & $38 \%$ \\
\hline YouTube & 38 & $23 \%$ \\
\hline Outros & 6 & $4 \%$ \\
\hline
\end{tabular}

Fonte: Dados da pesquisa

Outra intenção deste bloco de perguntas direcionado à comunicação era compreender de que maneira os consumidores geralmente descobrem as clínicas de estética no município em foco. De acordo com os resultados obtidos 
(TABELA 6), 60\% dos respondentes afirmaram que tomam conhecimento sobre este tipo de serviço por meio das redes sociais, enquanto 33\% alegam ficar sabendo através da indicação de amigos e conhecidos, o famoso "boca a boca", que tende a ser mais digno de crédito do que as fontes comerciais (KOTLER; ARMSTRONG, 2015). A título de curiosidade, destaca-se que na opção "Outros" (1\%) foram mencionados os influenciadores digitais e que nenhum dos entrevistados assinalou a alternativa "Materiais impressos".

Tabela 6 - Canais de descoberta de clínicas de estética.

\begin{tabular}{l|c|c}
\hline Canais de descoberta de clínicas de estética & Número & Percentual \\
\hline Redes sociais & 98 & $60 \%$ \\
\hline Indicação de amigos e conhecidos & 53 & $33 \%$ \\
\hline Busca na internet & 5 & $3 \%$ \\
\hline Anúncio & 2 & $1 \%$ \\
\hline Ao passar próximo ao estabelecimento & 2 & $1 \%$ \\
\hline Outros & 2 & $1 \%$ \\
\hline TOTAL & 162 & $100 \%$ \\
\hline
\end{tabular}

Fonte: Dados da pesquisa

Um fato interessante observado a partir da tabela 6 é que as principais formas de descoberta de clínicas de estética indicadas pelos entrevistados correspondem aquilo que Kotler e Keller (2012) determinam como "grupos de referência". Esses grupos, segundo os mesmos autores, expõem as pessoas a novos comportamentos e estilos de vida, influenciam suas atitudes e autoimagem e criam uma pressão por aceitação social que impacta diretamente nas escolhas de um produto ou serviço.

É valido ressaltar que os dados expostos na tabela 6 também oferecem pistas de como os clientes de clínicas de estética reconhecem uma necessidade e buscam as informações, etapas pertinentes ao processo de decisão de compra (KOTLER; ARMSTRONG, 2015). Para Kotler e Armstrong (2015), as redes sociais e os amigos ou conhecidos são alguns dos vários estímulos externos capazes de desencadear uma necessidade no consumidor, ao mesmo tempo que podem servir de fonte de informação para quem procura saber mais sobre um procedimento estético.

Por último, buscou-se identificar o canal preferido dos consumidores para se relacionar com uma clínica de estética. Nesse ponto, a opinião dos entrevistados ficou dividida entre as redes sociais (49\%) e o WhatsApp (48\%), o que reforça a importância desses meios digitais, tanto na promoção dos serviços, quanto na construção de um relacionamento mais próximo com os clientes (KOTLER; ARMSTRONG, 2015). Com percentuais quase inexpressivos, estão aqueles que preferem ir pessoalmente no local $(2 \%)$ ou manter contato pelo 
aplicativo do estabelecimento (1\%). Já as opções "Website" e "Telefone" não foram selecionadas. Assim, o ideal é buscar estratégias para que a comunicação seja compreensível e absorvida rapidamente, uma vez que a velocidade é uma constante nesse mundo tecnológico.

\subsection{Atributos valorizados na escolha de uma clínica de estética}

Esta última etapa da pesquisa visou averiguar quais atributos são valorizados pelos consumidores na escolha de uma clínica de estética em Santa Cruz do Sul (TABELA 7). Para tal, solicitou-se aos participantes que avaliassem a importância de 15 atributos, selecionados conforme explicado no tópico sobre procedimentos metodológicos, sendo 1 para pouco importante e 5 para muito importante.

Tabela 7 - Atributos valorizados na escolha de uma clínica de estética.

\begin{tabular}{l|c|c}
\hline Atributos & Média & Desvio Padrão \\
\hline Eficácia / Resultado do procedimento & 4,91 & 0,28 \\
\hline Limpeza / Higiene & 4,91 & 0,30 \\
\hline Profissionais qualificados & 4,90 & 0,31 \\
\hline Gentileza no atendimento & 4,77 & 0,44 \\
\hline Compromisso com o horário marcado & 4,76 & 0,44 \\
\hline Conforto nas instalações & 4,57 & 0,53 \\
\hline Ambiente que assegura a privacidade & 4,52 & 0,67 \\
\hline Equipamentos / Procedimentos modernos & 4,50 & 0,58 \\
\hline Atendimento personalizado & 4,49 & 0,63 \\
\hline Horários convenientes de atendimento & 4,48 & 0,64 \\
\hline Preço dos procedimentos & 4,42 & 0,71 \\
\hline Promoções & 4,30 & 0,81 \\
\hline Variedade de procedimentos oferecidos & 4,04 & 0,81 \\
\hline Localização conveniente & 3,99 & 0,89 \\
\hline Disponibilidade de estacionamento & 3,64 & 0,94 \\
\hline
\end{tabular}

Fonte: Dados da pesquisa

Analisando a tabela 7, percebe-se que os três atributos que mais influenciam na decisão por determinada clínica de estética são: empatados em primeiro lugar, a eficácia/resultado do procedimento $(4,91)$ e a limpeza/ higiene $(4,91)$; e em terceiro, profissionais qualificados $(4,90)$. Nesse sentido, investir na capacitação dos profissionais e incluir formas de evidenciar os efeitos proporcionados pelo tratamento ao paciente são práticas primordiais 
para as clínicas que desejam manter-se competitivas no mercado, além, é claro, de atentar à questão da higiene.

Já a variedade de procedimentos oferecidos $(4,04)$, localização conveniente $(3,99)$ e a disponibilidade de estacionamento $(3,64)$ são os aspectos menos relevantes. Em outras palavras, por mais que um leque diversificado de serviços e a facilidade de acesso agregue valor ao negócio, na avaliação dos entrevistados, eles não são suficientemente fortes para definir a compra.

Ao trazer o mix de marketing citado por Kotler e Armstrong (2015) para a discussão, é possível observar que os três principais atributos estão totalmente vinculados à dimensão "produto", o que demonstra o quanto os clientes são exigentes com relação à qualidade do serviço prestado. Em contrapartida, dois dos três atributos com menor importância se referem à "praça". Ainda assim essa perspectiva merece destaque, já que, além do fato da limpeza/higiene também se estender ao local, o conforto nas instalações $(4,57)$ e a privacidade do ambiente $(4,52)$ atingiram pontuações consideráveis.

$\mathrm{O}$ "preço", por sua vez, figura entre os fatores menos expressivos. Isto significa que a maioria dos entrevistados estão dispostos a pagar por serviços de estética independente da quantia que será cobrada. Da mesma forma, os participantes julgam que as promoções, umas das táticas do componente "promoção" mais utilizadas para atrair clientes, têm pouco impacto na escolha do estabelecimento.

Considerando que, geralmente, antes de tomar uma decisão final, os consumidores avaliam as alternativas de compra na busca de identificar aquela que lhes entregará o maior valor (CHURCHILL; PETER, 2000), as informações presentes na tabela 7 são de grande valia para as clínicas de estética do município. Afinal, ao conhecer os atributos mais relevantes e a importância que os consumidores conferem a cada um deles, os empresários podem construir ou adaptar o seu mix de marketing para corresponder a toda essa expectativa de valor e, assim, alcançar a satisfação dos seus clientes.

\section{CONSIDERAÇÕES FINAIS}

$\mathrm{O}$ intuito do presente trabalho foi investigar o comportamento dos clientes de clínicas de estética de Santa Cruz do Sul. Procurou-se, a partir dos dados colhidos na pesquisa, apresentar as principais características dos consumidores que frequentam esses estabelecimentos e proporcionar uma visão mais abrangente acerca das suas necessidades, preferências e hábitos de compra.

Dentre as descobertas do estudo, destaca-se que o público que mais consome serviços de estética no município é composto por mulheres relativamente jovens, que recebem de um a quatro salários mínimos. Como se pode notar, a renda mensal de boa parte dos participantes não é muito alta, o 
que indica que, de fato, a melhora da aparência deixou de ser um luxo para se tornar uma escolha ao alcance de todos.

Com a pesquisa, constatou-se também que o tipo de procedimento mais procurado pelos consumidores é o embelezamento. Já as principais queixas são gordura localizada, celulite e acne, sendo a acne a patologia mais comum entre as mulheres mais jovens, e as rugas e a flacidez entre aquelas com mais de 45 anos. Nesse contexto, salienta-se que as clínicas de estética da cidade têm como desafio aumentar a frequência de visita dos consumidores. Isso porque, apesar de considerarem os gastos com serviços estéticos necessários, a maioria dos entrevistados vai ao local sem periodicidade definida.

Outro achado significativo é que os consumidores geralmente tomam conhecimento de uma clínica de estética através das redes sociais ou da indicação boca a boca. Aliás, as empresas do ramo que desejam manter um relacionamento mais próximo com os clientes precisam ter uma presença ativa nas redes sociais e no WhatsApp, os dois canais de comunicação favoritos do público.

Mais do que isso, descobriu-se que, na opinião dos consumidores, os atributos mais valorizados na escolha de uma clínica de estética são a eficácia/ resultado do procedimento, a limpeza/higiene e profissionais qualificados. Assim, além de manter a higiene do espaço, investir em capacitação profissional e buscar formas de comprovar os efeitos dos tratamentos são pontos-chave para se diferenciar da concorrência e conquistar os clientes.

Por fim, acredita-se que as informações apresentadas neste artigo servem de suporte para os empresários locais na tomada de decisão e no planejamento de estratégias de marketing mais assertivas para o seu negócio. Consumidores com diferentes idades requerem tratamentos distintos e, portanto, os gestores de clínicas de estética devem conhecer a fundo seus clientes para ofertar serviços alinhados com a expectativa de cada público.

É importante enfatizar, porém, que o estudo tem limitações. A aplicação da pesquisa ocorreu apenas no ambiente online, o que pode ter deixado de fora alguns consumidores, sobretudo aqueles com idade mais avançada. Além disso, a amostra contou, basicamente, com mulheres e adultos jovens. Por isso, para estudos futuros, sugere-se trabalhar com uma amostragem maior e mais equilibrada, que permita conhecer também o comportamento de compra dos homens e da terceira idade, já que a participação desses públicos no mercado de estética cresce a cada dia.

\section{REFERÊNCIAS}

ABF. Associação Brasileira de Franchising. Desempenho do Franchising

Brasileiro em 2018. 2019. Disponível em: <https:/ /www.abf.com.br/wp-content/ uploads/2019/02/Desempenho-do-Franchising-Brasileiro-em-2018-e-estudo-sobreMicrofranquias.pdf>. Acesso em: 18 mai. 2019. 
ABIHPEC. Associação Brasileira da Indústria de Higiene Pessoal, Perfumaria e Cosméticos; SEBRAE. Serviço Brasileiro de Apoio às Micro e Pequenas Empresas. Caderno de Tendências 2019 - 2020: Higiene Pessoal, Perfumaria e Cosméticos. 2018. Disponível em: <https: / / abihpec.org.br/publicacao/caderno-detendencias-2019-2020> Acesso em: 18 mai. 2019.

ABIHPEC. Associação Brasileira da Indústria de Higiene Pessoal, Perfumaria e Cosméticos. Panorama do Setor de Higiene Pessoal, Perfumaria e Cosméticos 2019. 2019 Disponível em: <https:/ / abihpec.org.br/publicacao/panorama-do-setor-2019>. Acesso em: 18 mai. 2019.

AMA. American Marketing Association. Definitions of Marketing. 2017. Disponível em: <https:/ / www.ama.org/the-definition-of-marketing>. Acesso em: 18 mai. 2019.

BLACKWELL, Roger D.; MINIARD, Paul W.; ENGEL, James F. Comportamento do consumidor. São Paulo: Pioneira Thomson Learning, 2005.

CAMPOMAR, Marcos Cortez; IKEDA, Ana Akemi. O planejamento de marketing e a confecção de planos: dos conceitos a um novo produto. São Paulo: Saraiva, 2006.

CHURCHILL, Gilbert A.; PETER, J. Paul Marketing: criando valor para os clientes. São Paulo: Saraiva, 2000.

DIAS, Sergio Roberto. Gestão de marketing. São Paulo: Saraiva, 2003.

FERREL, O.C.; HARTLINE, M.D. Estratégia de marketing. São Paulo: Cengage Learning, 2008.

FUTRELL, Charles M. Vendas: fundamentos e novas práticas de gestão. São Paulo: Saraiva, 2003.

GIL, Antônio Carlos. Como elaborar projeto de pesquisa. 6. ed. São Paulo: Atlas, 2018.

KOTLER, Philip; ARMSTRONG, Gary. Princípios de marketing. 15. ed. São Paulo: Pearson Education do Brasil, 2015.

KOTLER, Philip; KELLER, Kevin L. Administração de Marketing. 14. ed. São Paulo: Pearson Education do Brasil, 2012.

MALHOTRA, Naresh K. Pesquisa de Marketing: uma orientação aplicada. 7. ed. Porto Alegre: Bookman, 2019.

MENEGUZZI, Pauline. Análise da satisfação de consumidoras de clínica estética na cidade de Esteio. 2016. 85 f. Dissertação (Programa de Pós-Graduação em Administração - Mestrado Profissional, Linha de Pesquisa em Gestão Estratégica de Marketing) - Universidade de Santa Cruz do Sul, Santa Cruz do Sul, 2016. 
RIBEIRO, José Luis Duarte; THIESEN, João Paulo Kappaun, TINOCO, Maria Auxiliadora Cannarozzo. Determinantes da satisfação e atributos da qualidade em serviços de salão de beleza. Produção, v. 23, n. 3, p. 609-624, jul./ set. 2013.

SEBRAE. Serviço Brasileiro de Apoio às Micro e Pequenas Empresas. A profissionalização dos centros de estética. 2017. Disponível em: <https:/ / www. sebrae.com.br/sites/PortalSebrae/artigos/a-profissionalizacao-dos-centros-de-estetic a,00a9d62b2b886410VgnVCM1000003b74010aRCRD>. Acesso em: 18 mai. 2019.

SOLOMON, Michael R. O comportamento do consumidor: comprando, possuindo e sendo. 9. ed. Porto Alegre: Bookman, 2011.

SPC BRASIL. Serviço de Proteção ao Crédito; CNDL. Confederação Nacional de Dirigentes Lojistas. Significados da beleza: autoimagem e consumo. 2016. Disponível em: <https://www.spcbrasil.org.br/wpimprensa/wp-content/uploads/2016/06/ Analise_mercado_beleza-1.pdf>. Acesso em: 18 mai. 2019.

VERGARA, Sylvia Constant. Projetos e relatórios de pesquisa em administração. 16. ed. São Paulo: Atlas, 2016. 